\title{
Influence of Acacia catechu Extracts and Urea and Gamma Irradiation on the Mechanical Properties of Starch/PVA-Based Material
}

\author{
Marufa Naznin, ${ }^{1}$ Md. Zainul Abedin, ${ }^{1}$ Mubarak Ahmad Khan, ${ }^{2}$ and Md. Abdul Gafur ${ }^{3}$ \\ ${ }^{1}$ Department of Environmental Science, Independent University, Bangladesh, Bashundhara, Dhaka, Bangladesh \\ ${ }^{2}$ Institute of Radiation and Polymer Technology, Atomic Energy Research Establishment, \\ Savar, Dhaka, Bangladesh \\ ${ }^{3}$ Power Plant and Product Development Center, BCSIR, Dhaka, Bangladesh \\ Correspondence should be addressed to Md. Zainul Abedin, zainul_abedin.iub73@yahoo.com
}

Received 31 August 2012; Accepted 18 September 2012

Academic Editors: L. Averous, T. R. Chantara, S. Fakirov, and A. Mousa

Copyright () 2012 Marufa Naznin et al. This is an open access article distributed under the Creative Commons Attribution License, which permits unrestricted use, distribution, and reproduction in any medium, provided the original work is properly cited.

This work was aimed to study the effect of natural polyphenol extract (Acacia catechu) on physicochemical properties of starch/PVA-based film. Acacia catechu extracts were incorporated in the starch/PVA- $(60: 40 \%)$ based films at different concentrations $(0.1 \%$ to $15 \%)$ to the total weight of starch/PVA-based film. The tensile strength (TS) of the starch/PVA blend film was $24 \mathrm{MPa}$ and significantly increased $(33.8 \mathrm{MPa})$ by the addition of acacia $(0.5 \%)$. Different percentages of urea $(1 \%$ to $15 \%)$ were incorporated in the starch/PVA/acacia-based film. The best tensile strength $(11 \mathrm{MPa})$ and elongation at break (59\%) were obtained at 5\% urea concentration. This 5\% urea-incorporated film was irradiated at different radiation doses; the film showed the best results at $100 \mathrm{krad}$ (tensile strength $15 \mathrm{MPa}$ and elongation at break 69\%). Molecular interactions due to incorporation of Acacia catech $u$ were supported by FTIR spectroscopy. Thermal properties (TG/DTA) of all the films were carried out successfully. Water absorption trend of all the films was comparatively high. Urea-incorporated film degraded $94 \%$, and irradiated urea incorporated film degraded $91 \%$ within 70 days into the soil.

\section{Introduction}

Pure starch lacks the tensile strength, processability, and dimensional stability, and when in a starch/PVA blend film, the percentage of starch is higher than PVA; the tensile strength of the film is relatively poor. Other effective means commonly used to modify the PVA/starch composites in order to improve their mechanical and water resistance properties include (1) chemically modifying PVA or starch [1], for example, esterification, oxidation, etherification, crosslinking, and methylation [2-8], (2) physically modifying the SP (starch/PVA) composites, for example, by adding corn fibers to the blends [9], or (3) chemically modifying the SP composites during or after the blending process, for example, cross-linking reactions, grafting $[10,11]$. Examples of crosslinking reagents include glutaraldehyde [12], boric acid [13], and epichlorohydrin [14], and those of methods include radiation [15] and photo-cross-linking [16]. However, crosslinking agents such as those mentioned above are costly and sometimes display toxicity. Thus, their potential applications in biodegradable packaging material are limited.

Catechu (or Khair), a hot water extract of red heartwood of Acacia catechu [17], is a brown-colored material with a bitter taste. It belongs to the family Leguminosae-mimosaceae. It has some medicinal values and is abundantly grown in the region of South Asian countries. The solution of Acacia cat$e c h u$ is acidic in nature. Acacia catechu extracts contain from $13 \%$ to $33 \%$ catechin which is a polyphenolic compound and from $22 \%$ to $50 \%$ tannic acid, which is called catechutannicacid. Besides these, water-soluble extractive matter, gum, and mineral substances are also found to be present [18]. Catechin and quercetin are polyphenolic compounds which also proved to increase the mechanical properties of the polymeric films. It has no problem of toxicity, and the 
ultimate goal of the production of environment friendly polymer will be fulfilled.

When the film contains a higher amount of starch than PVA in the blend, it becomes markedly brittle at lowmoisture content [19-22]. The addition of a plasticizer agent to the film is required to overcome film brittleness, caused by high intermolecular forces. Plasticizers reduce these forces and increase the mobility of polymer chains, thereby improving flexibility and extensibility of the film. On the other hand, plasticizers generally decrease gas, water vapor, and solute permeability of the film and can decrease elasticity and cohesion [23-25]. Several authors used urea as a plasticizer in the polymeric film $[25,26]$.

Radiation technology has been used frequently to improve the properties of plastic products due to the chemical reaction among polymer molecules under irradiation $[27$, 28 ]. And as the incorporation of plasticizers usually decreases the strength of the film, it is necessary to irradiate the film in order to increase the strength of the polymeric film [29]. In this study, the effect of polyphenolic compounds from Acacia catechu extracts into the starch/PVA-based film was evaluated and the effect of urea as a plasticizer and gamma radiation as a cross-linker into the starch/PVA/acacia-based film was also studied.

\section{Materials and Methods}

2.1. Materials. Polyvinyl alcohol (PVA) (MW 145000) was purchased from Merck Schuchardt OHG, Hohenbrunn, Germany. Rice starch was collected from rice cooking waste of the kitchen. Acacia catechu was purchased from local market. Urea was also purchased from Merck Schuchardt OHG, Hohenbrunn, Germany.

\subsection{Methods}

2.2.1. Preparation of Starch/PVA/Acacia Film. Starch/PVAbased biodegradable polymer films were prepared by solutions casting. Starch and PVA were blended in hot water in a ratio of $(60: 40 \%)$ at $150^{\circ} \mathrm{C}$ for about 2 hours to form a homogeneous solution, and Acacia catechu extracts were incorporated in starch/PVA blends at $(0.1 \%-15 \%)$ to the total weight of starch/PVA film. The solutions were then poured on the silicon -paper-covered glass plate. The solutions were maintained in a thickness of $4 \mathrm{~mm}$ on the glass plate. After cooling the dried films at room temperature for 72 hours, they were peeled from the silicon cloth and cut into small pieces of length $70 \mathrm{~mm}$ and width $10 \mathrm{~mm}$, and the average thickness of the dried films was about $0.3 \mathrm{~mm}$. The film having best mechanical property was chosen for further investigation. Urea was incorporated in the optimized starch/PVA/acacia-based film at a percentage of $(0 \%-15 \%)$ to the total weight of starch/PVA/acaciabased film. The films were stored in desiccators at room temperature $\left(30^{\circ} \mathrm{C}\right)$ and at $\mathrm{RH} 65 \%$ prior to performing the measurements.

2.3. Gamma Irradiation of the Film. The starch/PVA/acacia/urea film having best mechanical property was chosen for irradiation by gamma rays $\left({ }^{60} \mathrm{Co}\right.$ gamma source, Inter Professional Investment Ltd, UK). The film was irradiated with $350 \mathrm{krad} / \mathrm{hr}$ dose rates at various total doses $(25 \mathrm{krad}-$ $500 \mathrm{krad}$ ), and after 24 hours, the mechanical, thermal, and water absorption properties and soil burial test of the films were studied.

\subsection{Property Measurement}

2.4.1. Tensile Properties. Tensile strength (TS) and elongation at break (EB) of the films were measured with universal testing machine (Hounsfield Series S, UK). Each piece of the film had a length of $20 \mathrm{~mm}$ and a width of $10 \mathrm{~mm}$. Crosshead speed was $2 \mathrm{~mm} / \mathrm{mi}$, $\mathrm{n}$ and gauge length was $20 \mathrm{~mm}$ with load capacity of $500 \mathrm{~N}$. ASTM D882 was followed for the tensile test, and five replicates were tested for each sample to assess the precision of the method. All the tests were carried out at $20^{\circ} \mathrm{C}$ and $50 \% \mathrm{RH}$.

2.5. Fourier Transform Infrared Spectroscope (FTIR). The IR spectra of the films were measured by FTIR spectrophotometer (Perkin Elmer, UK). The FTIR spectrum was taken in an absorbance mode. The spectra were obtained at a resolution of $8 \mathrm{~cm}^{-1}$ in the range of 650 to $4000 \mathrm{~cm}^{-1}$.

2.6. Thermal Analysis. The thermal test of the films was performed using computer-controlled TG/DTA 6300 system controlled to an EXSTAR 6000 STATION, Seiko Instrument Inc., Japan. The TG/DTA module used a horizontal system balance mechanism. All the experiments were performed under the nitrogen atmosphere. Sample weights were $8 \mathrm{mg}-$ $10 \mathrm{mg}$ and heating rate was $10^{\circ} \mathrm{C} / \mathrm{min}$ within the temperature range of $50-600^{\circ} \mathrm{C}$.

2.6.1. Water Absorption. The water absorption of the films was monitored (up to 120 minutes) to find the profile of water uptake. Water absorption was determined using the following equation

$$
\mathrm{Wg}=\frac{(\mathrm{Wa}-\mathrm{Wo})}{\mathrm{Wo}} \times 100,
$$

where Wa and Wo were the weights of the sample after and before soaking in water.

2.7. Soil Burial Test. The degradation tendency of the films (both irradiated and nonirradiated) in the soil was studied. The films were buried in soil for 70 days. Moisture content of the soil was maintained at around $15 \%-18 \%$. In every week, samples were taken out from the soil. After cleaning carefully and drying at room temperature, their weight losses were measured [30, 31]. Weight losses (\%) were determined using the following equation:

$$
\mathrm{Wg}=\frac{(\mathrm{Wa}-\mathrm{Wo})}{\mathrm{Wa}} \times 100,
$$

where Wa and Wo were the weights of the sample before and after soil burial treatment. 


\section{Results and Discussion}

3.1. Effect of Acacia catechu (Ac) Extracts on the Mechanical Properties of Starch/PVA (St/PVA) Film. As polymer materials such as films may be subjected to various kinds of stress during being used, the study of the mechanical properties is of primary importance for determining the performance of the materials [32]. The tensile strength (TS) and elongation at break (EB) of blend films are plotted as a function of the Acacia catechu content which are shown in Figure 1.

Because polymer materials may be subjected to various kinds of stress in the process of usage, the determination of the mechanical properties involves not only scientific but also technological and practical aspects [33]. It has been observed that the TS of the film increased initially with the increase of Ac extracts content. The TS of St/PVA-based film is $24 \mathrm{MPa}$. When $0.1 \%$ Ac extracts were incorporated in the base film, the TS increased to $29 \mathrm{MPa}$. And at $0.5 \% \mathrm{Ac}$ extracts incorporated Starch/PVA film, it shows highest TS $(33.8 \mathrm{MPa})$, and the TS value remains almost constant up to $5 \%$ Ac extracts.

The improvement in mechanical properties of the films incorporated with Ac extracts may be attributed to the interaction between St/PVA and polyphenolic compounds from Ac extracts. There is a possibility that polyphenolic compounds may be able to fit into St/PVA base polymeric matrix and establish interactions such as hydrogen bonding with $\mathrm{OH}$ groups of St/PVA [34]. Changes in mechanical properties as affected by polyphenolic compounds were also observed for other biopolymeric films [35-37].

However, after a certain value, with the increase of Ac extracts into the St/PVA-based film, the TS of the film gradually decreases. This sharp decrease of TS at higher concentration of Ac may be due to lessening of compactness of the film components. As the percentage of catechuic acid and tannic acid increased in the St/PVA-based film, these can cause a breakdown in the structure of St/PVA based film.

In case of EB from Figure 1, it has also been found that no remarkable change in EB has occurred by the incorporation of Ac extracts in the St/PVA-based film. As the $0.5 \%$ Ac extracts-incorporated film exhibits highest TS $(33.8 \mathrm{MPa})$, this film was chosen for further investigation.

3.2. Fourier Transform Infrared Spectroscope (FTIR). FTIR is of importance in the study of the molecular structure. The width and intensity of the spectrum bands, as well as the position of the peaks, are all sensitive to environment changes and to the conformation of macromolecules on the molecular level. Intermolecular interaction occurs when different polymers are compatible, so that the FTIR spectrum of the blend is different from those of pure polymers, which is advantageous to the study of the extent of polymer compatibility.

Figure 2 represents the FTIR spectra of St/PVA-based film, Starch/PVA/Acacia based film, and pure Ac extracts. For Ac extracts, characteristic aromatic $\mathrm{C}=\mathrm{C}$ bending appears at $1618 \mathrm{~cm}^{-1}-1449 \mathrm{~cm}^{-1}$, at $1238 \mathrm{~cm}^{-1}-\mathrm{CH}$ bending vibration, and at $1075 \mathrm{~cm}^{-1}$ for $\mathrm{C}-\mathrm{O}$ stretching vibration. The characteristic peaks of St/PVA film are: $1418-1338 \mathrm{~cm}^{-1}$ for

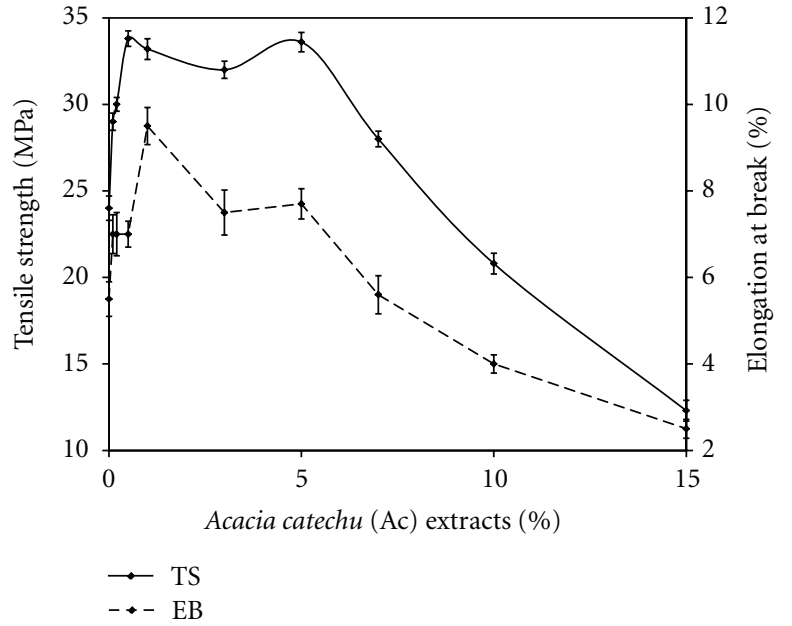

FIgURE 1: Effect of Acacia catechu (Ac) extracts on the tensile strength and elongation at break of St/PVA film.

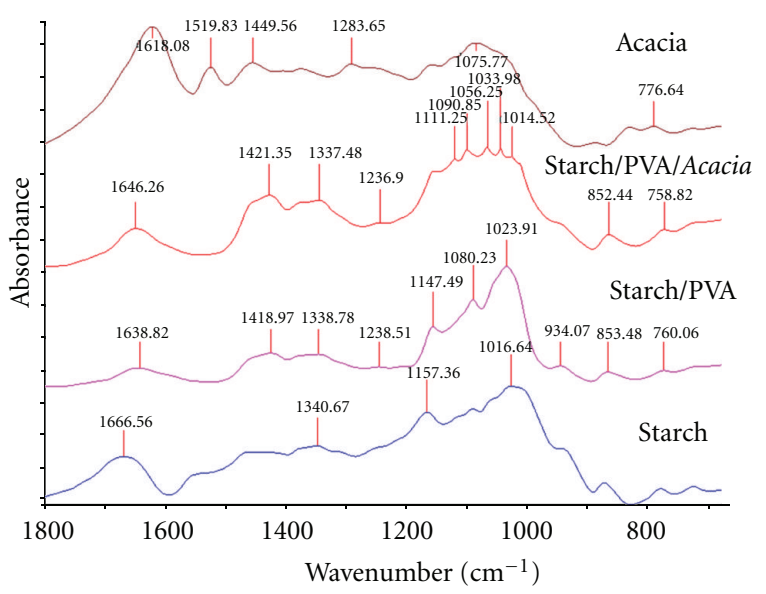

FIgUre 2: FTIR spectra of St/PVA, St/PVA/Ac, and Acacia catechu (Ac) extracts.

$\mathrm{CH}$ or $\mathrm{CH}_{2}$ bending vibration, $1080 \mathrm{~cm}^{-1}$ for $\mathrm{C}-\mathrm{O}$ stretching vibration and stretching vibration of $\mathrm{C}=\mathrm{C}$ at $1638 \mathrm{~cm}^{-1}$. However, after incorporation of Ac extracts into the St/PVAbased film, a trivial change occurs when compared to the spectrum of St/PVA and Ac extracts. Certain peaks of Ac extracts fade away, and some peaks are shifted from lower to slightly higher region than St/PVA film. In the starch/PVA/acacia (St/PVA/Ac) film, some high intensity peaks appeared in the $1111 \mathrm{~cm}^{-1}$ to $1014 \mathrm{~cm}^{-1}$ which indicate the strong intensity of $-\mathrm{C}-\mathrm{O}$ group. Furthermore, in the film of St/PVA and St/PVA/Ac, higher peaks are observed which are at $3349 \mathrm{~cm}^{-1}$ and $3354 \mathrm{~cm}^{-1}$, respectively (not shown in the figure). These two absorption bands correspond to $-\mathrm{OH}$ stretching vibration and $2931 \mathrm{~cm}^{-1}$ for -CH stretching vibration in both films [38]. 
3.3. Effect of Urea on the Mechanical Properties of Starch/PVA/ Acacia-(St/PVA/Ac-) Based Film. Urea has been incorporated into the St/PVA/Ac-based film to observe the mechanical properties of the film. The TS and EB of blend films are plotted as a function of the urea content which are shown in Figure 3. From these figures, it has been observed that the incorporation of urea in the base film leads to a gentle decrease of the TS of the film with the increase of urea content, while it increases significantly the EB, as plasticizers are expected to reduce the modulus, tensile strength, hardness, and glass transition temperature but increase the flexibility and elongation at break of a polymer [39].

From Figure 3 it has been found that the TS and EB of the St/PVA/Ac-based film were $33 \mathrm{MPa}$ and 7\%, respectively. After incorporation of $1 \%$ urea the TS of the film has been found to decrease to $20 \mathrm{MPa}$ but the EB increased to $20 \%$. In this way, at $5 \%$ urea incorporation, the TS of the film decreased to $11 \mathrm{MPa}$, and the EB increased to $59 \%$, and at $10 \%$ urea, the TS is $5 \mathrm{MPa}$, and $\mathrm{EB}$ is $126.5 \%$. This behavior can be explained taking into consideration the fact that the increase of the plasticizer amount in the blend results in a greater mobility of both the starch and the PVA macromolecules which enhance the flexibility of the resulting film [40]. However, when $15 \%$ urea has been incorporated, the TS and EB simultaneously decrease to $2 \mathrm{MPa}$ and $47 \%$, respectively. It was observed that in these materials, increasing the amount of plasticizer led to a reduction in the elongation at rupture; however, in general a rise in plasticizer content should increase the EB [41].

3.4. Effect of Gamma Irradiation on the Mechanical Properties of St/PVA/Ac/Urea-Based Film. St/PVA/Ac/urea blend films were irradiated under gamma radiation at different doses $(25,50,100,200$, and $500 \mathrm{krad})$ at a dose rate of $350 \mathrm{krad} / \mathrm{hr}$ to determine the effect of gamma irradiation on the mechanical property of the St/PVA/Ac/urea blend films. The TS and EB of gamma-irradiated films are plotted as a function of the radiation doses which are shown in Figure 4. Figure 4 illustrates the effect of gamma radiation on ureaincorporated St/PVA/Ac-based film. It has been observed that in the nonirradiated film, the TS and $\mathrm{EB}$ were $11 \mathrm{MPa}$ and $60 \%$. At $25 \mathrm{krad}$ radiation dose, the TS and the EB of the film increased to $12 \mathrm{MPa}$ and $62 \%$ and continuously increase with the increase of radiation dose up to $100 \mathrm{krad}$. And in this $100 \mathrm{krad}$ radiation, the TS increased to $15 \mathrm{MPa}$ and $\mathrm{EB}$ to $69 \%$.

Radiation dose produces a denser network structure because of increased cross-linking, which ultimately leads to the enhancement of mechanical properties such as TS, hardness, and softening temperature. After radiation maybe both the oxygen of the $\mathrm{C}-\mathrm{O}-\mathrm{H}$ group and the oxygen of the $\mathrm{C}-\mathrm{O}-\mathrm{C}$ group in starch could form hydrogen bonds with the amide group of urea [26]. As the radiation dose was increased to $200 \mathrm{krad}$, the TS decreased to $13.5 \mathrm{MPa}$, and the EB decreased to 55\%. And the same behavior was found at $500 \mathrm{krad}$ radiation dose. With the increase of radiation dose, the decreases of these mechanical properties are due to the disruption of denser network structure of the composite polymer.

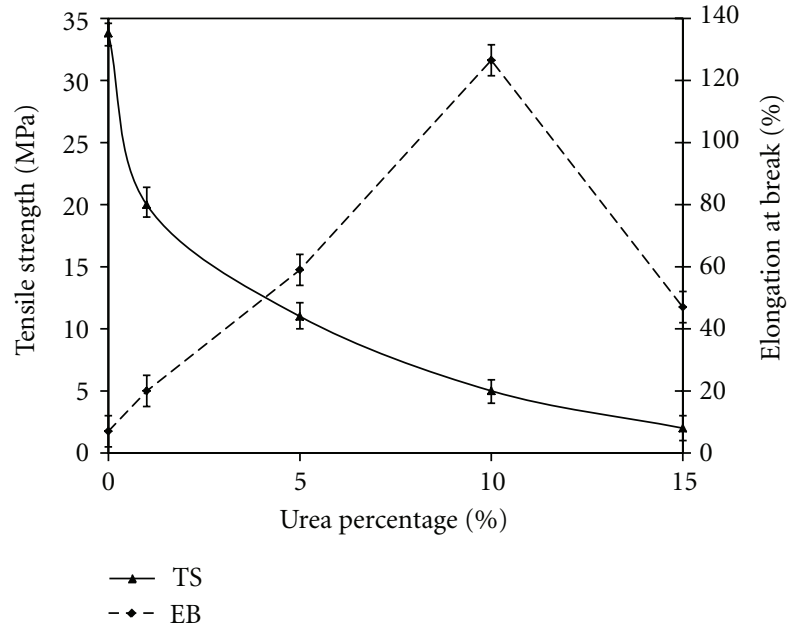

FIGURE 3: Effect of urea on the tensile strength and elongation at break of St/PVA/Ac film.

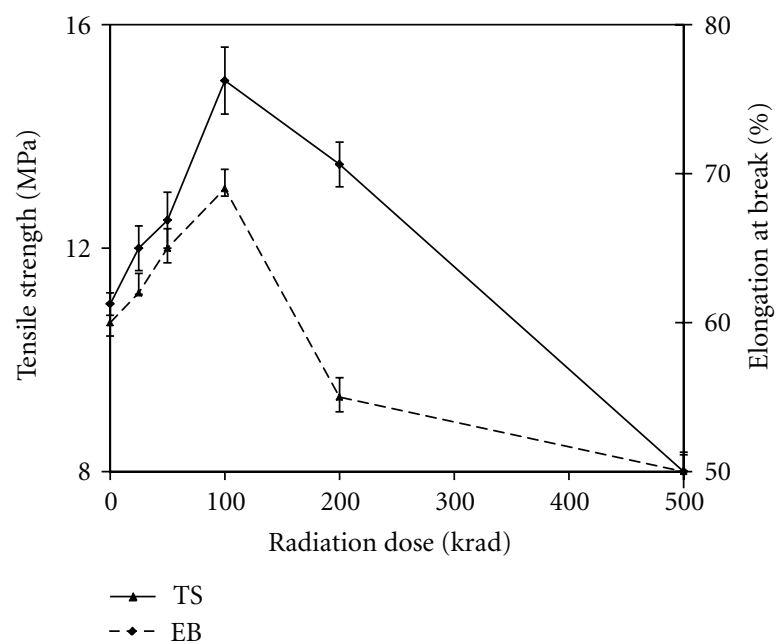

FIGURE 4: Effect of gamma radiation on the tensile strength and elongation at break St/PVA/Ac/urea film.

3.5. Water Absorption. Figure 5 represents the water absorption of St/PVA, St/PVA/Ac, and St/PVA/Ac/urea and irradiated $\mathrm{St} / \mathrm{PVA} / \mathrm{Ac} / \mathrm{Urea}$ film. Water uptake was measured by soaking the films in static glass beakers contained deionized water at room temperature $\left(25^{\circ} \mathrm{C}\right)$ for different time series $(1,3,5,10,20,40$, and 60 minutes $)$.

As starch is a water-sensitive material and the percentage of starch is higher in the entire blend film, the percentage of water absorption is also higher. From the figure, it has been found that the incorporation of acacia slightly increases the level of water absorption, but the incorporation of urea cause a major change in the curve of water absorption. But when the urea-incorporated film was irradiated, the level of water absorption again decreased. During the first few minutes of immersion, both the films (St/PVA and St/PVA/Ac) absorb about $45 \%$ and $48 \%$ of water correspondingly. After 5 , 10, 20, 40, and 60 minutes, St/PVA films absorb 77, 146, 147,157 , and $183 \%$ of water, respectively, while St/PVA/Ac 


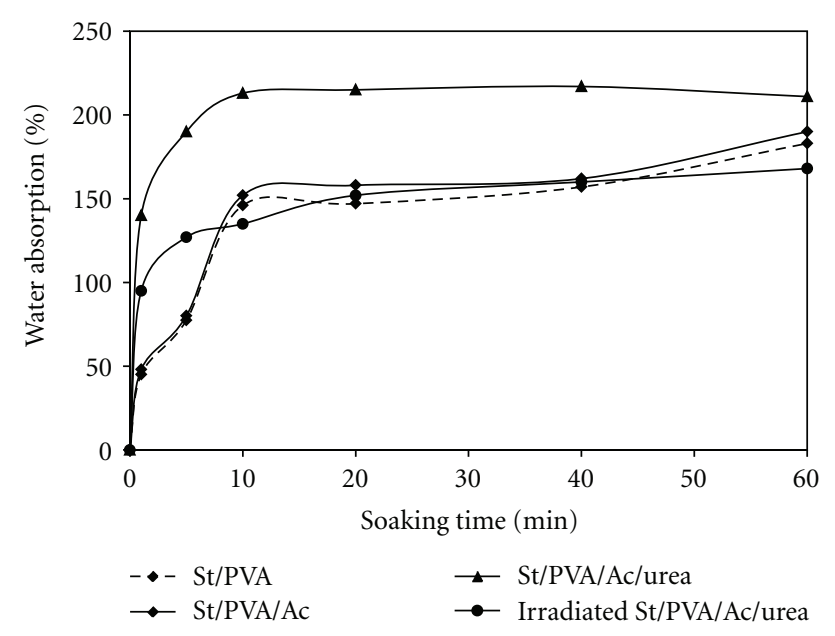

FIGURE 5: Comparison of water absorption of the St/PVA, St/PVA/ Ac, St/PVA/Ac/urea, and irradiated St/PVA/Ac/urea-based film.

base film absorb $80,152,158,162$, and $190 \%$ of water. Both films are still absorbing water and more stable in the water. Again, after 1, 5, 10, 20, 40, and 60 minutes, the St/PVA/Ac/urea film absorbs 140, 190, 213, 215, 217, and $211 \%$ of water and gradually loses its weight in the water. But the irradiated St/PVA/Ac/urea film within the same time interval absorbs $95,127,135,152,160$, and $168 \%$ of water. And the level of absorption increases with the increase of immersion time. This is may be due to the fact that because of cross-linking, polysaccharide chain of starch and $\mathrm{OH}-$ groups of PVA and urea create a three-dimensional compact structure. Therefore, there is very little opportunity for the water molecule to be associated or absorbed within the irradiated film. Thus, the irradiated samples showed less water uptake [30].

\subsection{Thermal Properties}

3.6.1. TG. Figure 6 represents the thermogravimetry of $\mathrm{St} / \mathrm{PVA}, \mathrm{St} / \mathrm{PVA} / \mathrm{Ac}, \mathrm{St} / \mathrm{PVA} / \mathrm{Ac} / \mathrm{urea}$, and irradiated St/PVA/ Ac/urea film. From the gravimetry curve, it was found that the incorporation of acacia, urea, and then irradiation did not made any significant changes in the thermal property. The incorporation of acacia has slightly improved the thermal stability of the film, but the incorporation of urea and gamma irradiation did not contribute any changes in the thermal stability of the film.

From the figure, it has been found that each film shows two degradation steps. The first step of weight loss could be attributed to the loss of loosely bound water, accompanied by the formation of volatile-disintegrated products. The second step was mainly caused by the thermal decomposition of the molecules, and the products were composed of small molecular carbon and hydrocarbon [30]. St/PVA-based film shows two major degradation stages, the onset of melting occurred at $285^{\circ} \mathrm{C}$ where the film lost its $13 \%$ weight and the offset of melting occurred at $364^{\circ} \mathrm{C}$, and it degraded its $83 \%$ weight, and a $50 \%$ degradation took place at $324^{\circ} \mathrm{C}$. In

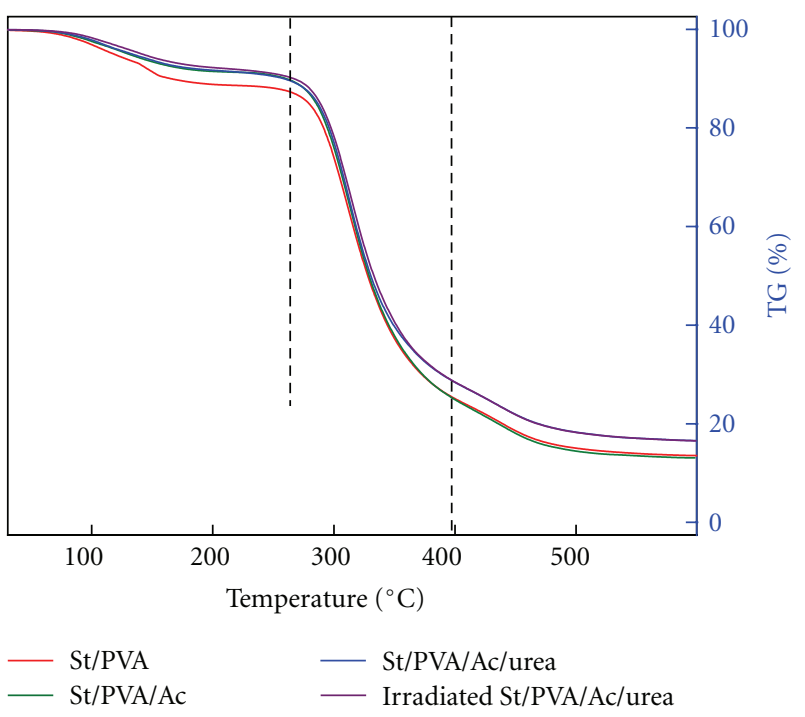

Figure 6: Comparison of TG of St/PVA, St/PVA/Ac, St/PVA/Ac/ urea, and irradiated St/PVA/Ac/urea film.

the St/PVA/Ac, the onset of melting occurred at $285^{\circ} \mathrm{C}$ where the film lost its $9 \%$ weight, and offset of melting occurred at $364^{\circ} \mathrm{C}$ and it degraded its $84 \%$ weight, and $50 \%$ degradation took place at around $327^{\circ} \mathrm{C}$.

$\mathrm{St} / \mathrm{PVA} / \mathrm{Ac} /$ urea-based film, the onset of melting occurred at $268^{\circ} \mathrm{C}$ where the film lost its $11 \%$ weight, and offset of melting occurred at $355^{\circ} \mathrm{C}$, and it degraded its $76 \%$ weight, and $50 \%$ degradation took place at $330^{\circ} \mathrm{C}$, whereas in the irradiated St/PVA/Ac/urea-based film, the onset of melting occurred at $289^{\circ} \mathrm{C}$ where the film lost its $10 \%$ weight, and offset of melting occurred at $358^{\circ} \mathrm{C}$, and it degraded its $76 \%$ weight, and $50 \%$ degradation took place $330^{\circ} \mathrm{C}$. So the thermogravimetry data shows almost similar properties, and any noticeable change has not been observed here.

3.6.2. DTA. Figure 7 represents the differential thermal analysis of St/PVA, St/PVA/Ac, St/PVA/Ac/urea, and irradiated St/PVA/Ac/urea film. The incorporation of acacia has slightly improved the thermal stability of the film, but the incorporation of urea reduces thermal stability of the film. Figure 9 shows that the DTA curve of St/PVA film depicts two endothermic peaks at $104^{\circ} \mathrm{C}(1.78 \mathrm{uV})$ and at $303^{\circ} \mathrm{C}$ $(5.36 \mathrm{uV})$, which indicate the melting and decomposition temperatures, respectively. The incorporation of acacia in the St/PVA film increases the melting point and decomposition temperature, and it occurred at $118^{\circ} \mathrm{C}(1.66 \mathrm{uV})$ and at $314^{\circ} \mathrm{C}(4.43 \mathrm{uV})$. This is because the polyphenol of acidic acacia binds with the macromolecule of starch and form compact structure which increases the thermal stability of the film. Again, the DTA curve of the St/PVA/Ac/urea film shows its melting point and decomposition point at $115^{\circ} \mathrm{C}$ $(-0.91 \mathrm{uV})$ and at $312^{\circ} \mathrm{C}(3.00 \mathrm{uV})$.

Homogeneous polymer mixtures with a crystallizable component usually show a decrease in experimental melting points with the addition of the amorphous component, 


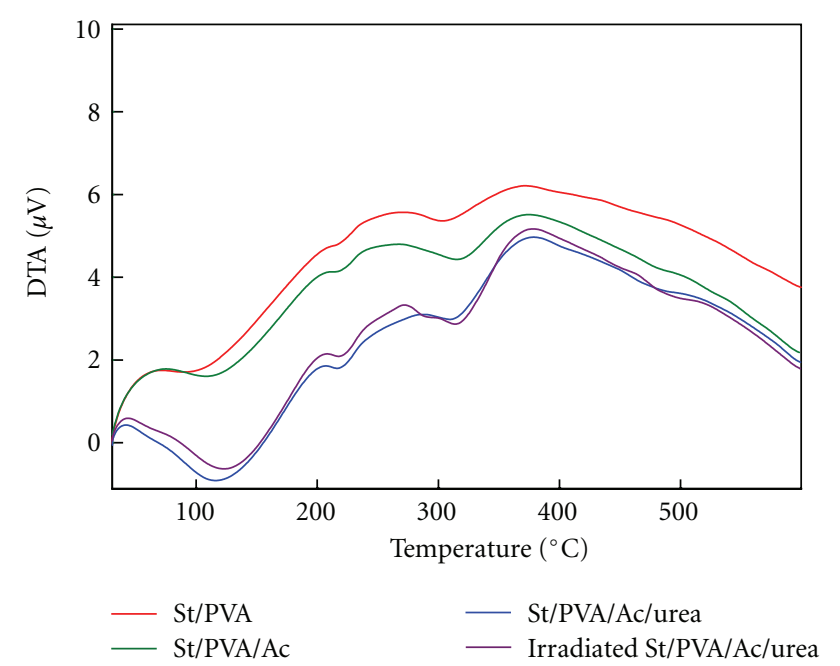

Figure 7: Comparison of DTA of St/PVA, St/PVA/Ac, St/PVA/Ac/ urea, and irradiated St/PVA/Ac/urea film.

because the interaction of the two polymers reduces the crystallite size. Significant changes of DTA curves of the blend films suggested the strong interactions among starch, PVA, and urea molecules [30]. The irradiated St/PVA/Ac/Urea film depicts its melting point and decomposition point at $124^{\circ} \mathrm{C}$ $(-0.63 \mathrm{uV})$ and at $313^{\circ} \mathrm{C}(2.87 \mathrm{uV})$. So after irradiation, the thermal stability of the film slightly increased.

3.6.3. DTG. Figure 8 shows the differential thermogravimetry of St/PVA, St/PVA/Ac, St/PVA/Ac/urea, and irradiated St/PVA/Ac/urea film. DTG curve of the starch/PVA-based film depicts one predominant peak at $315^{\circ} \mathrm{C}$, where the maximum degradation rate was $1.262 \mathrm{mg} / \mathrm{min}$. DTG curve of the St/PVA/Ac-based film depicts the predominant peak at $314^{\circ} \mathrm{C}$, where the maximum degradation rate was $1.042 \mathrm{mg} / \mathrm{min}$; with urea-incorporated film, the degradation rate increased to $2.386 \mathrm{mg} / \mathrm{in}$ at $312^{\circ} \mathrm{C}$, and the irradiated St/PVA/Ac/urea film shows the degradation rate of $2.702 \mathrm{mg} / \mathrm{min}$ at $317^{\circ} \mathrm{C}$ temperature. From the figure, it is evident that urea incorporation lowers the thermal stability whereas the irradiated St/PVA/Ac/urea film shows a slightly higher stability than nonirradiated film. The incorporation of urea reduces the degradation temperature of St/PVA/Ac blends, which means the decomposition of macromolecular starch to enhance the plasticity of blend [42].

3.7. Soil Biodegradation. Figure 9 shows the comparison of soil biodegradability of nonirradiated and irradiated St/PVA/ Ac/urea films. These films were buried into the soil to study the degradation trend. The films were weighted individually and buried in garden soil for 1 to 70 days. Moisture content of the soil was maintained at around $15 \%-18 \%$. After these periods, the films were withdrawn cautiously from the soil, washed, dried, and reweighed. At the end, the weight loss of the samples was calculated. From the figure, it has been found that irradiated urea incorporated film shows lower degradation rate than the nonirradiated film.

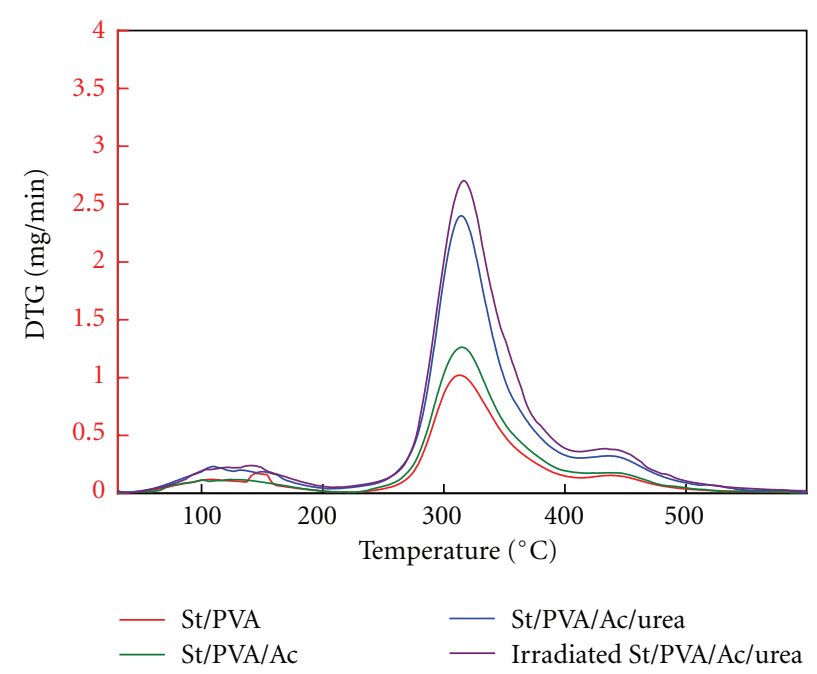

Figure 8: Comparison of DTG of St/PVA, St/PVA/Ac, St/PVA/Ac/ urea, and irradiated St/PVA/Ac/urea film.

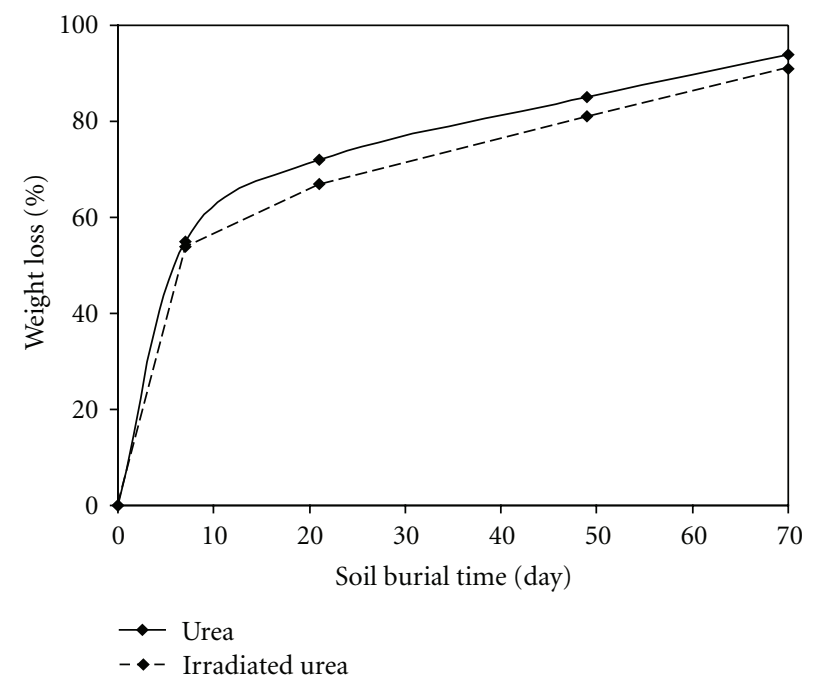

FIGURE 9: Comparison of weight loss in soil burial test of irradiated and nonirradiated St/PVA/Ac/urea film.

At initial stage, the biodegradation rate was higher. The weight loss is influenced by the composition of the blend, and by the nature of the microorganisms. The highest values of weight loss were obtained due to the high content of starch. During biodegradation, spherical holes appear due to colonization by the degrading microorganisms. The starch is first consumed by microorganisms, together with the amorphous part of PVA. When the starch was almost fully degraded, the PVA was also further degraded, but its speed was slower than that of the starch molecule [31]. The weak biodegradability of PVA could be partly caused by the structure of the PVA (unknown stereoregularity of hydroxyl groups) or by the degree of polymerization (comparably high molecular weight).

From Figure 9, it has been observed that urea-incorporated film degraded faster than irradiated film. At 7 days, 
irradiated film loss was $54 \%$, and the nonirradiated film loss, $55 \%$ after 21 days, the weight loss reached to $67 \%$ for previous and $72 \%$ for latter. Finally, after 70 days of burial time, irradiated film loss was $91 \%$, and the nonirradiated film loss was $94 \%$. The degradability of the gammairradiated film was slightly lower than that of the nonradiated film, as because of cross-linking, the gamma-irradiated film produces a compact structure, which degraded at a lower speed.

\section{Conclusion}

Addition of Ac extracts in starch/PVA- $(60: 40)$ based films contributed to the improvement of their mechanical properties. This St/PVA/Ac-based film lacks elongation property, so further treatment was carried out with different percentage of urea, and it has been found that 5\% urea-incorporated film shows optimum mechanical property (tensile strength $11 \mathrm{MPa}$ and elongation at break 59\%). Exposition of this $\mathrm{St} / \mathrm{PVA} / \mathrm{Ac} / \mathrm{urea}$ film to gamma radiation revealed that at $100 \mathrm{krad}$ TS and EB of the film increased to $15 \mathrm{MPa}$ and 69\%, respectively, compared to nonirradiated film. From TGA analysis, it was found that urea addition in St/PVA/Ac-based films increased the thermal decomposition, which indicates lowering of thermal stability, but after gamma irradiation, thermal stability slightly increased. The water absorption behavior of St/PVA- and St/PVA/Ac-based film shows almost a similar trend. When urea was added into the St/PVA/Acbased film, the absorption rate highly increased, and after irradiation, the water uptake rate dramatically reduced. The soil burial test of 70 days showed that the irradiated ureaincorporated film degrades $91 \%$, and the nonirradiated one degrades $94 \%$.

\section{Acknowledgment}

The authors thank the staff of Institute of Radiation and Polymer Technology, Bangladesh Atomic Energy Commission for technical support and advice throughout the work.

\section{References}

[1] Y. U. Nabar, D. Draybuck, and R. Narayan, "Physicomechanical and hydrophobic properties of starch foams extruded with different biodegradable polymers," Journal of Applied Polymer Science, vol. 102, no. 1, pp. 58-68, 2006.

[2] D. Demirgöz, C. Elvira, J. F. Mano, A. M. Cunha, E. Piskin, and R. L. Reis, "Chemical modification of starch based biodegradable polymeric blends: effects on water uptake, degradation behaviour and mechanical properties," Polymer Degradation and Stability, vol. 70, no. 2, pp. 161-170, 2000.

[3] S. Kiatkamjornwong, P. Thakeow, and M. Sonsuk, "Chemical modification of cassava starch for degradable polyethylene sheets," Polymer Degradation and Stability, vol. 73, no. 2, pp. 363-375, 2001.

[4] M. Kim, "Evaluation of degradability of hydroxypropylated potato starch/ polyethylene blend films," Carbohydrate Polymers, vol. 54, no. 2, pp. 173-181, 2003.

[5] M. Kim and S. J. Lee, "Characteristics of crosslinked potato starch and starch-filled linear low-density polyethylene films," Carbohydrate Polymers, vol. 50, no. 4, pp. 331-337, 2002.
[6] I. M. Thakore, S. Desai, B. D. Sarawade, and S. Devi, "Studies on biodegradability, morphology and thermo-mechanical properties of LDPE/modified starch blends," European Polymer Journal, vol. 37, no. 1, pp. 151-160, 2001.

[7] Y. Xu, V. Miladinov, and M. A. Hanna, "Synthesis and characterization of starch acetates with high substitution," Cereal Chemistry, vol. 81, no. 6, pp. 735-740, 2004.

[8] Z. Guohua, L. Ya, F. Cuilan, Z. Min, Z. Caiqiong, and C. Zongdao, "Water resistance, mechanical properties and biodegradability of methylated-cornstarch/poly(vinyl alcohol) blend film," Polymer Degradation and Stability, vol. 91, no. 4, pp. 703-711, 2006.

[9] P. Cinelli, E. Chiellini, J. W. Lawton, and S. H. Imam, "Foamed articles based on potato starch, corn fibers and poly(vinyl alcohol)," Polymer Degradation and Stability, vol. 91, no. 5, pp. 1147-1155, 2006.

[10] M. K. Beliakova, A. A. Aly, and F. A. Abdel-Mohdy, "Grafting of poly(methacrylic acid) on starch and poly(vinyl alcohol)," Starch, vol. 56, no. 9, pp. 407-412, 2004.

[11] R. Jayasekara, I. Harding, I. Bowater, G. B. Y. Christie, and G. T. Lonergan, "Preparation, surface modification and characterisation of solution cast starch PVA blended films," Polymer Testing, vol. 23, no. 1, pp. 17-27, 2004.

[12] B. Ramaraj, "Crosslinked poly(vinyl alcohol) and starch composite films. II. Physicomechanical, thermal properties and swelling studies," Journal of Applied Polymer Science, vol. 103, no. 2, pp. 909-916, 2007.

[13] Y. Yin, J. Li, Y. Liu, and Z. Li, "Starch crosslinked with poly(vinyl alcohol) by boric acid," Journal of Applied Polymer Science, vol. 96, no. 4, pp. 1394-1397, 2005.

[14] B. Sreedhar, D. K. Chattopadhyay, M. S. H. Karunakar, and A. R. K. Sastry, "Thermal and surface characterization of plasticized starch polyvinyl alcohol blends crosslinked with epichlorohydrin," Journal of Applied Polymer Science, vol. 101, no. 1, pp. 25-34, 2006.

[15] M. Zhai, F. Yoshii, and T. Kume, "Radiation modification of starch-based plastic sheets," Carbohydrate Polymers, vol. 52, no. 3, pp. 311-317, 2003.

[16] N. Follain, C. Joly, P. Dole, and C. Bliard, "Properties of starch based blends. Part 2. Influence of poly vinyl alcohol addition and photocrosslinking on starch based materials mechanical properties," Carbohydrate Polymers, vol. 60, no. 2, pp. 185-192, 2005.

[17] S. S. Bhatnagar, "The Wealth of India," C.S.I.R. India, vol. 1, p. 8, 1948.

[18] A. Rahman, M. S. Hakim, and V. Ahmad, Pakistan Encyclopaedia Planta Medica, vol. 1, Hamdard Pakistan, 1986.

[19] R. A. Talja, H. Helén, Y. H. Roos, and K. Jouppila, "Effect of various polyols and polyol contents on physical and mechanical properties of potato starch-based films," Carbohydrate Polymers, vol. 67, no. 3, pp. 288-295, 2007.

[20] R. A. Talja, H. Helén, Y. H. Roos, and K. Jouppila, "Effect of type and content of binary polyol mixtures on physical and mechanical properties of starch-based edible films," Carbohydrate Polymers, vol. 71, no. 2, pp. 269-276, 2008.

[21] C. H. Chen and L. S. Lai, "Mechanical and water vapor barrier properties of tapioca starch/decolorized hsian-tsao leaf gum films in the presence of plasticizer," Food Hydrocolloids, vol. 22, no. 8, pp. 1584-1595, 2008.

[22] D. F. Parraa, C. C. Tadinib, P. Poncea, and A. B. Lugãoa, "Mechanical properties and water vapor transmission in some blends of cassava starch edible films," Carbohydrate Polymers, vol. 58, no. 4, pp. 475-481, 2004. 
[23] N. Gontard, S. Guilbert, and J. L. Cuq, "Water and glycerol as plasticizers affect mechanical and water vapor barrier properties of an edible wheat gluten film," Journal of Food Science, vol. 58, no. 1, pp. 206-211, 1993.

[24] P. J. A. Sobral, F. C. Menegalli, M. D. Hubinger, and M. A. Roques, "Mechanical, water vapor barrier and thermal properties of gelatin based edible films," Food Hydrocolloids, vol. 15, no. 4-6, pp. 423-432, 2001

[25] X. F. Ma, J. G. Yu, and J. Feng, "A mixed plasticizer for the preparation of thermoplastic starch," Chinese Chemical Letters, vol. 15, no. 6, pp. 741-744, 2004.

[26] X. Ma and J. Yu, "The effects of plasticizers containing amide groups on the properties of thermoplastic starch," Starch, vol. 56, no. 11, pp. 545-551, 2004.

[27] A. Bhattacharya, "Radiation and industrial polymers," Progress in Polymer Science, vol. 25, no. 3, pp. 371-401, 2000.

[28] J. Gehring, "With radiation crosslinking of engineering plastics into the next millennium," Radiation Physics and Chemistry, vol. 57, no. 3-6, pp. 361-365, 2000.

[29] M. Zhai, F. Yoshii, and T. Kume, "Radiation modification of starch-based plastic sheets," Carbohydrate Polymers, vol. 52, no. 3, pp. 311-317, 2003.

[30] F. Parvin, M. A. Khan, A. H. M. Saadat et al., "Preparation and characterization of gamma irradiated sugar containing starch/poly (vinyl alcohol)-based blend films," Journal of Polymer and Environment, vol. 19, no. 4, pp. 1013-1122, 2011.

[31] S. Tang, P. Zou, H. Xiong, and H. Tang, "Effect of nano- $\mathrm{SiO}_{2}$ on the performance of starch/polyvinyl alcohol blend films," Carbohydrate Polymers, vol. 72, no. 3, pp. 521-526, 2008.

[32] H. Tang, H. Xiong, S. Tang, and P. Zou, "A starch-based biodegradable film modified by nano silicon dioxide," Journal of Applied Polymer Science, vol. 113, no. 1, pp. 34-40, 2009.

[33] B. Li, J. F. Kennedy, Q. G. Jiang, and B. J. Xie, "Quick dissolvable, edible and heatsealable blend films based on konjac glucomannan-gelatin," Food Research International, vol. 39, no. 5, pp. 544-549, 2006.

[34] S. Rohn, H. M. Rawel, and J. Kroll, "Antioxidant activity of protein-bound quercetin," Journal of Agricultural and Food Chemistry, vol. 52, no. 15, pp. 4725-4729, 2004.

[35] J. Gómez-Estaca, B. Giménez, P. Montero, and M. C. GómezGuillén, "Incorporation of antioxidant borage extract into edible films based on sole skin gelatin or a commercial fish gelatin," Journal of Food Engineering, vol. 92, no. 1, pp. 78-85, 2009.

[36] M. C. Gómez-Guillén, M. Ihl, V. Bifani, A. Silva, and P. Montero, "Edible films made from tuna-fish gelatin with antioxidant extracts of two different murta ecotypes leaves (Ugni molinae Turcz)," Food Hydrocolloids, vol. 21, no. 7, pp. 11331143, 2007.

[37] O. Orliac, A. Rouilly, F. Silvestre, and L. Rigal, "Effects of additives on the mechanical properties, hydrophobicity and water uptake of thermo-moulded films produced from sunflower protein isolate," Polymer, vol. 43, no. 20, pp. 5417-5425, 2002.

[38] X. Han, S. Chen, and X. Hu, "Controlled-release fertilizer encapsulated by starch/polyvinyl alcohol coating," Desalination, vol. 240, no. 1-3, pp. 21-26, 2009.

[39] M. Rahman and C. S. Brazel, "The plasticizer market: an assessment of traditional plasticizers and research trends to meet new challenges," Progress in Polymer Science, vol. 29, no. 12, pp. 1223-1248, 2004.

[40] N. Tudorachi, C. N. Cascaval, M. Rusu, and M. Pruteanu, "Testing of polyvinyl alcohol and starch mixtures as biodegradable polymeric materials," Polymer Testing, vol. 19, no. 7, pp. 785-799, 2000.
[41] E. M. Teixeira, A. L. Da Róz, A. J. F. Carvalho, and A. A. S. Curvelo, "The effect of glycerol/sugar/water and sugar/water mixtures on the plasticization of thermoplastic cassava starch," Carbohydrate Polymers, vol. 69, no. 4, pp. 619-624, 2007.

[42] S. Y. Yang, C. I. Liu, J. Y. Wu, J. C. Kuo, and C. Y. Huang, "Improving the processing ability and mechanical strength of starch/poly(vinyl alcohol) blends through plasma and acid modification," Macromolecular Symposia, vol. 272, no. 1, pp. 150-155, 2008. 

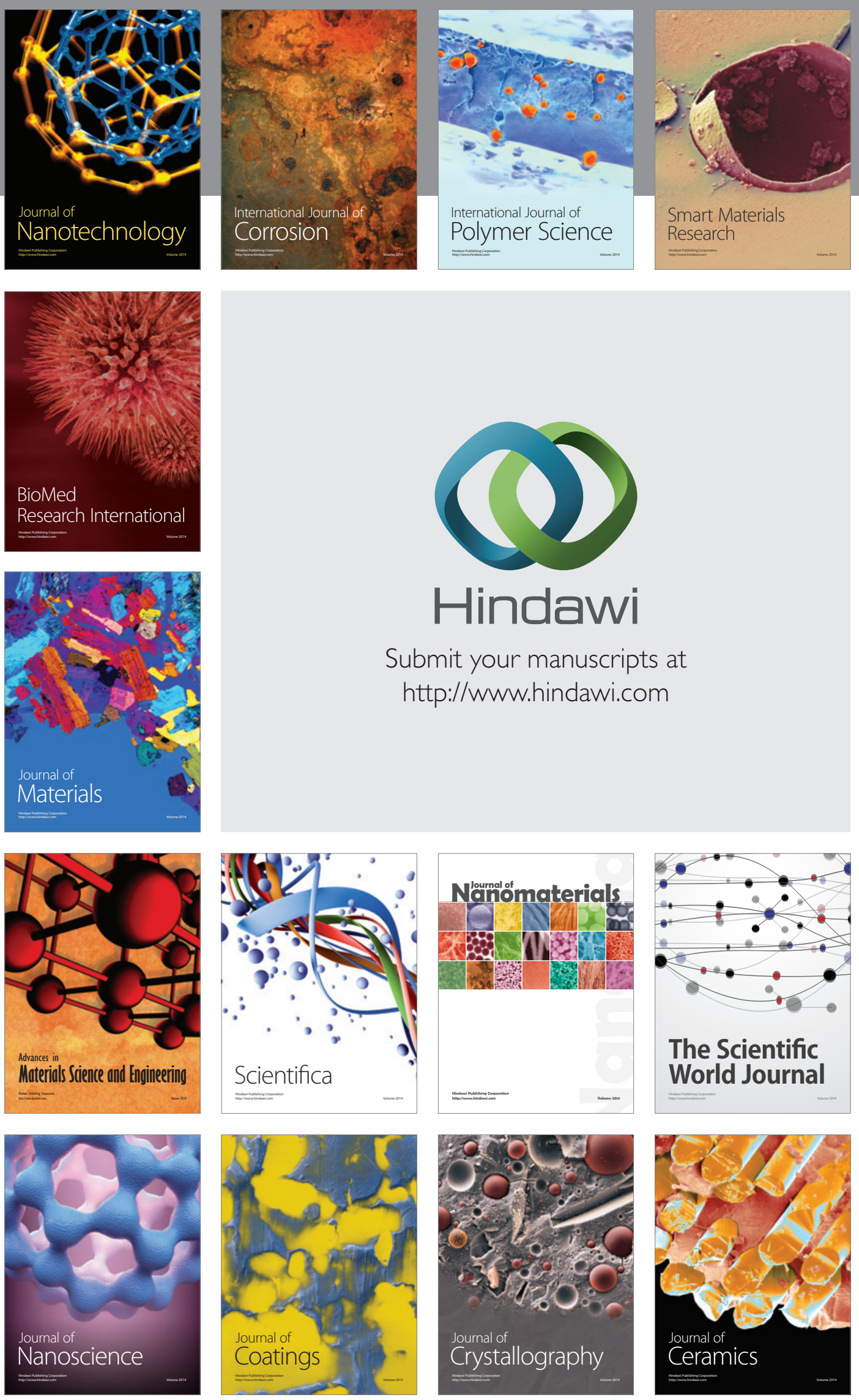

The Scientific World Journal

Submit your manuscripts at

http://www.hindawi.com

\section{World Journal}

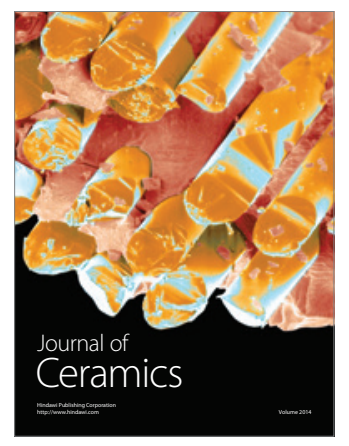

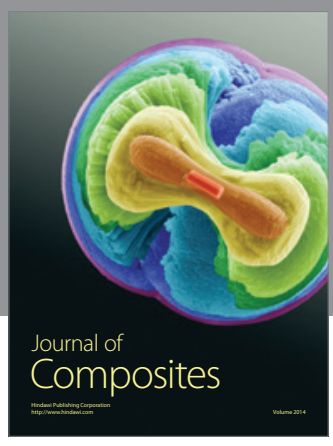
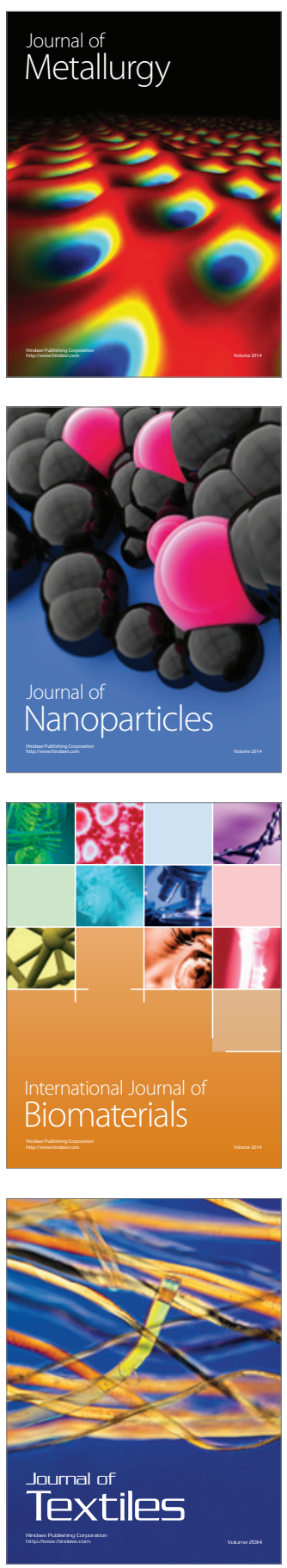